\title{
Sobre o amor entre mulheres: apontamentos sobre conjugalidade e sexualidade
}

\section{About love between women: notes on conjugality and sexuality}

\author{
Gabriela Boldrini da Silva (orcid.og/0000-0003-4336-4739)' \\ Maria Cristina Smith Menandro (orcid.og/ 0000-0003-4339-2975)²
}

\begin{abstract}
Resumo
O objetivo deste trabalho foi conhecer as características dos relacionamentos afetivo-sexuais entre mulheres. Trata-se de estudo descritivo de abordagem qualitativa, utilizando como instrumento entrevista com roteiro semiestruturado. Participaram cinco mulheres, com idades entre 25 e 37 anos, que estabelecem parceria afetivo-sexual com outra mulher, sob a forma de coabitação há no mínimo um ano. A análise qualitativa de inspiração fenomenológica identificou particularidades e pontos convergentes nas experiências relatadas. Os dados apontam que a trajetória de vida dessas mulheres é marcada por violências, enquanto a constituição de uma nova família é permeada por intenso afeto, companheirismo e parceria. Conhecer os relacionamentos entre mulheres é importante para a desmistificação de estigmas que ainda se atualizam sob a forma de violência contra mulheres lésbicas e bissexuais. Aponta-se que para pesquisas futuras seja interessante ampliar a faixa etária das participantes, bem como utilizar marcadores de classe e raça.
\end{abstract}

Palavras-chave: Conjugalidades. Lesbianidades. Lesbofobia. Sexualidade. Gênero.

\begin{abstract}
The objective of this work was to know the characteristics of affective-sexual relationships between women. This is a descriptive study with a qualitative approach, using a semi-structured interview as an instrument. The participants were five women, aged between 25 to 37 years, who have established an affective-sexual partnership with another woman, in the form of cohabitation for at least one year. The qualitative analysis of phenomenological inspiration identified particularities and convergent points in the reported experiences. The data indicate that the life trajectory of these women is marked by violence, while the constitution of a new family is permeated by intense affection, companionship and partnership. Knowing the relationships between women is important to demystify the stigmas that are still perpetuated in the form of violence against lesbians and bisexual women. It is pointed out that for future research it is interesting to expand the age range of the participants, as well as to use social class and race markers.
\end{abstract}

Key words: Conjugality. Lesbianism. Lesbophobia. Sexuality. Gender.

\footnotetext{
${ }^{1}$ Universidade Federal do Espírito Santo, Espírito Santo, Brasil. E-mail: gabrielaboldrini.psi@gmail.com.

${ }^{2}$ Universidade Federal do Espírito Santo, Espírito Santo, Brasil. E-mail: cristinasmithmenandro@gmail.com.
} 
Os estudos sobre conjugalidade começaram e se desenvolver no campo da Psicologia no século XX, e muitas e complementares são as definições acerca desse construto. FéresCarneiro (2001) aponta a importância do relacionamento conjugal na atribuição de significado à vida das pessoas, uma vez que é uma relação que envolve grande investimento afetivo e um alto grau de intimidade. De acordo com Heilborn (2004), a conjugalidade expressa uma relação social que condensa um "estilo de vida", fundamentado em uma dependência mútua. Já Nascimento, Scorsolini-Comin, Fontaine \& Santos (2015) definem a conjugalidade como o estabelecimento de união entre duas pessoas.

O avanço do campo de estudos sobre gênero e sexualidade suscitou entre pesquisadores da área da Psicologia o interesse em entender de que forma os conhecimentos psicológicos poderiam contribuir para os estudos de gênero e sexualidade. Foi a partir daí que se passou a focar no aspecto das relações humanas e, especificamente, da conjugalidade, por se tratar de um elemento essencial do ciclo de vida (Rodrigues \& Boeckel, 2016). É nesse contexto que, na década de 1970, o campo de estudos sobre conjugalidade passa a sofrer diversos desdobramentos teóricos e os estudos sobre as homoconjugalidades começam a ganhar força (Féres-Carneiro \& Neto, 2010).

Miskolci (2007) aponta que a identidade gay sempre foi vista como uma ameaça ao status quo, e, destarte, o casamento gay se revela como uma possibilidade que ameaça a ordem social, a reprodução biológica, a hierarquia entre os sexos, o meio para a transmissão de propriedade, a moralidade e os valores tradicionais de modo geral. Segundo Costa (1992 citado por Paiva, 2007), socialmente os homossexuais estão exilados do vocabulário da conjugalidade e da família, e vivencia-se hoje no Brasil uma intensa disputa discursiva acerca da família contemporânea, com embates que, de um lado, evidenciam defesas de uma suposta "família tradicional", que estaria em "crise" devido à "ideologia de gênero" empregada em torno dos avanços dos direitos das minorias sexuais; e de outro, discursos progressistas que ampliam o olhar sobre as possibilidades de configurações de arranjos familiares.

No caso da conjugalidade entre mulheres, é possível sublinhar algumas particularidades acerca desses relacionamentos. Por exemplo: tradicionalmente as mulheres elegem a conjugalidade como fator importante para suas vidas, ancorando-se na imagem de 
"vida a dois" que o amor romântico fabrica e incide sobre a constituição da feminilidade (Heilborn, 2004) - no senso comum, a conjugalidade é vista como condição para concretização da maternidade e, consequentemente, da identidade feminina de modo geral. A autora afirma ainda que as relações entre mulheres são demarcadas pelo senso comum por dois enunciados, o de invisibilidade e o de intraduzibilidade. O primeiro se refere a uma menor cultura pública da homossexualidade feminina, com menor quantidade de lugares públicos e menos referências explícitas, uma vez que a sexualidade feminina é desqualificada tradicionalmente; segundo se ancora na dificuldade que a maioria das pessoas tem em colocar em palavras a experiência lésbica.

Estudos recentes, como o de Luz (2015), apontam que as mulheres entrevistadas por ele revelam se sentirem constrangidas a constituírem uma família "tradicional", a se denominarem como casal. Outros estudos, como os de Defendi (2010) e Paiva (2007), apontam que o relacionamento amoroso aparece como fundamental para a definição da identidade sexual de homens gays, uma vez que é a partir dele que ocorre a descoberta e a autoaceitação da homossexualidade. Em contrapartida, as pesquisas de Luz (2015) e Meinerz (2011) revelam que a identidade lésbica não parece estar associada à estabilização de um relacionamento conjugal.

Entretanto, é importante ressaltar que faltam referências que sirvam como base para discutir a realidade dos casais de mulheres, uma vez que a maioria dos estudos recentes se remete à homoconjugalidade masculina. Tal viés é apontado por Luz (2015) e também por Heilborn (2004): a autora afirma que, apesar de estudos sobre conjugalidade homossexual datarem de mais de duas décadas, a produção nacional sobre a homossexualidade feminina é em menor quantidade e abrangência do que aqueles estudos que se referem à homossexualidade masculina.

\section{Política do esquecimento e existência lésbica}

O termo "lésbica" - utilizado para se referir às mulheres que se relacionam afetiva e sexualmente com outras mulheres - foi registrado pela primeira vez em 1842 . O uso desse termo aparece inicialmente como forma de diferenciação e inferiorização das mulheres que 
não seguiam o padrão heterossexual, podendo, nos diversos contextos históricos, se referir a uma prática, a um sentimento, a um crime/pecado, a uma doença ou, mais recentemente, a uma identidade (Toledo \& Filho, 2010).

No Brasil, a homossexualidade passou a ser condenada no período inquisitório, sob a forma do Tribunal do Santo Ofício, julgando aquilo que considerava como "delitos morais" e "desvios de conduta familiar ou sexual". Já no século XIX, com o avanço da Medicina, a sexualidade da mulher passou a ser tratada como sintoma de histeria.

Os discursos médicos e religiosos fundamentaram uma visão estigmatizante acerca dos relacionamentos entre mulheres, pois, a partir deles, foi extraída boa parte dos discursos que recaem sobre as mulheres que se relacionam com outras mulheres, quer sejam: os argumentos de que, de alguma maneira, essas mulheres experienciaram relações afetivo-sexuais frustrantes com homens; que a homossexualidade é uma "fase"; que a mulher lésbica deseja ser homem; que as mulheres não são capazes de sentirem prazer sexual; que a mulher lésbica é "frustrada" e "insegura" por não conseguir desenvolver uma esperada "feminilidade"; que duas mulheres juntas nunca poderão ser plenamente completas e satisfeitas sexualmente; e que, por fim, toda mulher precisa de um homem para ser feliz.

Além disso, sabe-se também que, no senso comum, a lésbica é considerada um sujeito que está fora da categoria "mulher", tendo características associadas a comportamentos tidos como masculinos, como violência e perversão (Souza, 2012). As explicações causais também são comuns nos discursos que tentam explicar a homossexualidade; é comum escutar explicações que vão desde argumentos biológicos (quantidade desajustada de hormônio, genética, formas corporais) a causas psicossociais (relações familiares desestruturadas, abuso na infância etc.).

Outra ideia bastante difundida no senso comum, e também na literatura e nas Ciências Sociais, é de que as mulheres se dirigem naturalmente para os homens, como uma espécie de "comportamento inato", e a lésbica simplesmente demonstra sua amargura diante dos homens (Rich, 2010). Há uma forte tentativa de fazer as mulheres se odiarem, quer seja no âmbito heterossexual, no qual a competição entre mulheres pelos homens é estimulada, quer seja no âmbito homossexual, no qual o amor entre duas mulheres é constantemente deslegitimado e forçado a se esconder. 
Portanto, apreender a experiência das conjugalidades entre mulheres se faz necessário, uma vez que esses relacionamentos têm especificidades, que devem ser assinaladas, e ainda são relegados à condição de subalternidade, consequência da posição de invisibilidade que a mulher lésbica ocupa na sociedade.

\section{Metodologia}

Este é um estudo descritivo de abordagem qualitativa, sob a forma de estudo fenomenológico, abordando primordialmente o significado das ações, atitudes e relações humanas de modo geral. Participaram deste estudo cinco mulheres, que estabelecem parceria afetivo-sexual com outra mulher, coabitando há no mínimo um ano. A idade das participantes variou entre 25 e 37 anos, com níveis diversos de escolaridade, renda e configuração familiar. A quantidade de participantes foi definida seguindo as recomendações de Sá (1998 citado por Coutinho, 2008), sobre o critério de saturação, no qual o fim da fase de coleta se dá quando os temas começam a se repetir nas entrevistas.

O instrumento utilizado para a coleta de dados teve como base um roteiro semiestruturado de entrevista, que apreendeu os seguintes núcleos de informações: história e características do relacionamento, processo de constituição da identidade sexual, vivências de preconceito/discriminação, redes de suporte e apoio social, dinâmica e conflitos conjugais e perspectivas para o futuro.

Para a análise dos dados, foi utilizado o método fenomenológico, que, segundo Trindade, Menandro e Gianórdoli-Nascimento (2007), busca a experiência tal como ela foi ou é vivenciada. De acordo com Andrade e Holanda (2010), o método fenomenológico é um recurso que vem sendo utilizado pela Psicologia como forma de apreender o universo vivenciado pelo sujeito, tendo como finalidade investigar o sentido e/ou o significado da experiência para a pessoa em determinada situação. Em síntese, pode ser definido como "uma forma de pesquisa orientada à descoberta de significados expressos por um sujeito sobre sua experiência" (Decastro \& Gomes, 2011, p. 155).

Para a presente pesquisa, o método fenomenológico demonstrou-se apropriado para apreender o enredo de ramificações da experiência da conjugalidade entre mulheres. Tendo 
como porta-vozes essas mulheres, buscou-se principalmente possibilitar a visibilidade dessas relações, distanciando-se de medidas comparativas ou de atribuição de significados e aproximando-se da experiência vivida genuinamente por tais sujeitas.

\section{Resultados e discussão}

O Quadro 1 apresenta uma caracterização geral das entrevistadas, com informações retiradas dos questionários de dados sociodemográficos e das entrevistas. Os nomes das participantes são fictícios e foram escolhidos pela própria pesquisadora: Luana, Mickaely, Sibel, Laís e Dayane.

Quadro 1. Dados gerais das participantes

\begin{tabular}{|c|c|c|c|c|c|}
\hline & Luana & Mickaely & Sibel & Laís & Dayane \\
\hline Idade & 25 & 30 & 29 & 31 & 37 \\
\hline Escolaridade & $\begin{array}{c}\text { Superior } \\
\text { incompleto }\end{array}$ & $\begin{array}{l}\text { Pós-Graduação } \\
\text { completa }\end{array}$ & $\begin{array}{c}\text { Superior } \\
\text { incompleto }\end{array}$ & $\begin{array}{l}\text { Fundamental } \\
\text { incompleto }\end{array}$ & $\begin{array}{c}\text { Pós- } \\
\text { Graduação } \\
\text { completa }\end{array}$ \\
\hline Profissão & Estudante & Professora & Estudante & Diarista & $\begin{array}{l}\text { Assistente } \\
\text { Social }\end{array}$ \\
\hline $\begin{array}{l}\text { Renda } \\
\text { familiar }\end{array}$ & $\begin{array}{l}\text { Até } 2 \text { salários } \\
\text { mínimos }\end{array}$ & $\begin{array}{l}\text { Até } 2 \text { salários } \\
\text { mínimos }\end{array}$ & $\begin{array}{l}\text { Até } 2 \text { salários } \\
\text { mínimos }\end{array}$ & $\begin{array}{l}\text { Até } 2 \text { salários } \\
\text { mínimos }\end{array}$ & $\begin{array}{l}\text { De } 2 \text { a } 4 \\
\text { salários } \\
\text { mínimos }\end{array}$ \\
\hline Raça/cor & Branca & Branca & Branca & Parda & Parda \\
\hline $\begin{array}{c}\text { Tempo de } \\
\text { relacionamen } \\
\text { to }\end{array}$ & 3 anos & $\begin{array}{c}5 \text { anos e } 4 \\
\text { meses }\end{array}$ & 5 anos e 5 meses & 5 anos & 1 ano e meio \\
\hline $\begin{array}{l}\text { Tempo de } \\
\text { coabitação }\end{array}$ & $\begin{array}{c}2 \text { anos e } 8 \\
\text { meses }\end{array}$ & 2 anos & 5 anos & 5 anos & 1 ano \\
\hline $\begin{array}{c}\text { Motivos para } \\
\text { coabitação }\end{array}$ & $\begin{array}{l}\text { Precisava de } \\
\text { alguém para } \\
\text { dividir as } \\
\text { contas }\end{array}$ & $\begin{array}{l}\text { Problemas de } \\
\text { relacionamento } \\
\text { com o pai }\end{array}$ & $\begin{array}{l}\text { Vontade de } \\
\text { passar mais } \\
\text { tempo juntas }\end{array}$ & $\begin{array}{l}\text { Conflitos com } \\
\text { o ex-marido }\end{array}$ & $\begin{array}{c}\text { Queria } \\
\text { alguém para } \\
\text { Ihe fazer } \\
\text { companhia }\end{array}$ \\
\hline $\begin{array}{c}\text { Relação } \\
\text { assumida }\end{array}$ & Não & Sim & Sim & Sim & Sim \\
\hline $\begin{array}{l}\text { Como define } \\
\text { a relação }\end{array}$ & $\begin{array}{c}\text { Companheiris } \\
\text { mo e } \\
\text { confiança }\end{array}$ & $\begin{array}{c}\text { Parceria, } \\
\text { companheirism } \\
\text { o, amizade }\end{array}$ & $\begin{array}{c}\text { Muito amor e } \\
\text { companheirismo }\end{array}$ & Não sabe & $\begin{array}{c}\text { Parceria muito } \\
\text { grande }\end{array}$ \\
\hline
\end{tabular}




\begin{tabular}{|c|c|c|c|c|c|}
\hline $\begin{array}{c}\text { Identidade } \\
\text { sexual }\end{array}$ & Sem definição & Lésbica & Lésbica & Sem definição & Lésbica \\
\hline
\end{tabular}

Fonte: Elaborado pelas autoras.

As participantes deste estudo têm características diversas, no que tange à dinâmica conjugal dos seus relacionamentos e ao modo como se referem a ele e às suas parceiras. Entretanto, existe um ponto comum evidente entre elas que aproxima os relacionamentos aqui retratados: quase todas definem suas relações como sendo permeadas por muito companheirismo e parceria. Esse é um dado já retratado em diversas pesquisas realizadas sobre relacionamentos entre mulheres (Muniz, 1992; Féres-Carneiro, 1999; Heilborn, 2004; Meinerz, 2011; Luz, 2015), o que nos permite avaliar esse elemento como primeiro e importante a ser discutido.

A etimologia da palavra "parceria" é entendida aqui como uma forma de sociabilidade que abarca, entre outras coisas, uma atividade sexual/afetiva (Meinerz, 2011). Além disso, uma relação que se diz pautada no companheirismo e na parceria presume assimilar características de cuidado e apoio mútuo, e nos discursos das participantes podemos perceber isso em diversos momentos, algumas inclusive afirmando se constituírem um casal extremamente "grudado", que faz tudo - ou quase tudo - junto.

Heilborn (2004) aponta que os relacionamentos entre mulheres enunciam certa sensibilidade particular, com uma possível exacerbação do significado social atribuído à "mulher". Sendo a mulher em nossa sociedade considerada aquela que "cuida", e tendo a ideia de amor romântico como algo a ser alcançado por todas as mulheres, a autora reflete que no amor entre duas mulheres a afetividade é levada às últimas consequências - ao mesmo tempo que um namoro pode rapidamente se transformar em casamento, o casamento se redimensiona facilmente para a amizade, e a ênfase no companheirismo pode surgir como maneira de prolongar e proteger esse vínculo.

Outro fator comum presente na realidade de quatro das cinco participantes é com relação à decisão pela coabitação, que ocorreu de maneira quase concomitante ao início do relacionamento. Conforme retratado por uma das participantes, existe um ditado popular que diz que "lésbica é assim, né, namorou já casou”, podendo ser esse fator entendido como 
um recurso de enfrentamento à invisibilização e à opressão social sofridas pelas mulheres que se relacionam com mulheres. Afinal, isso evidencia também uma das prerrogativas apontada há muito pelos estudos de gênero e pelos movimentos feministas: as mulheres, de modo geral, têm maneiras distintas de vivência da sexualidade, se comparada à experienciada pelos homens, pois desde a primeira infância à menina é destinado o desconhecimento com relação ao seu próprio corpo e é censurada toda e qualquer forma de expressão erótica (Moreno, 1999).

Portanto, se para as mulheres que se relacionam com homens a vivência da sexualidade já é algo continuamente cerceado, às lésbicas recaem ainda mais restrições, uma vez que vivenciam uma sexualidade marginalizada socialmente. Dessa forma, a falta de apoio familiar e, consequentemente, a necessidade de se viver "às escondidas" refletem uma combinação de fatores que, para esses casais, pode urgir no imediato compartilhamento do espaço reservado à expressão da intimidade de maneira segura: o próprio lar. Nossas entrevistadas relatam que foram expostas a situações vexatórias quando ousaram expressar seus afetos em ambientes públicos ou em ambientes privados considerados inseguros (casa dos pais, por exemplo). Sendo assim, essas mulheres veem seus relacionamentos se designando de maneira tão sigilosa e invisível que o compartilhamento do ambiente doméstico pode acabar surgindo como única possibilidade de vivência desse afeto, conforme relatado por nossa participante Sibel.

Aí ela começou a dormir lá em casa, aí minha mãe começou a falar que não podia, né [...]. [Ela] já tava com algumas roupas até lá em casa, ela já tava dormindo com alguma frequência, mas não era uma coisa pensada, acabou que foi indo. Aí a gente decidiu [...]. Na verdade, inicialmente eu pensei em terminar, falei não vai dar certo, eu vou ficar me apaixonando e a gente não vai poder se ver, vou terminar, mas não terminei [risos]. Aí a gente decidiu morar junto, pra ficar mais tempo junto mesmo.

Entretanto, apontar essas nuances não significa afirmar que há ausência de desejo nesse fundar-se enquanto casal que coabita. Pelo contrário, nossas participantes demonstram sentimentos genuínos e profundos por suas parceiras, fazendo questão de 
reafirmarem sempre a escolha de permanecerem juntas. Mas essa reflexão faz-se necessária a fim de que se considerem os mecanismos inconscientes que podem estar presentes por trás de um padrão recorrente, que, nesse caso, podem refletir a expressão das marcas da opressão de gênero.

Além disso, a emergência do "morar junto" ou "casar" com outra mulher nem sempre vem atrelada à constituição da identidade sexual dessas mulheres, demonstrando ser necessário que se discutam os complexos fatores que levam à afirmação de uma identidade sexual, uma vez que essa é uma das dimensões centrais na constituição da identidade social dos sujeitos. É possível afirmar a existência de certo distanciamento entre as primeiras experiências homoeróticas e a singularização de uma identidade - distanciamento esse comumente marcado por intensos enunciados negativos provenientes de diversos instituições como a família, a escola e a religião.

Segundo Paiva (2007), a assunção da homossexualidade encontra-se permeada por uma metafísica do não ser/ser, sendo que essa construção entre não ser/ser faz parte do desenvolvimento da identidade sexual do sujeito, que se por um lado é marcada por inicial negação e sentimento de culpa pelo desejo sentido, por outro culmina em uma certeza daquilo que se é e sente. Por exemplo: Luana é a única entrevistada que não tem uma relação completamente "assumida" socialmente e é também a que tem uma identidade menos definida e mais efeitos discursivos de flagelação do relacionamento, uma vez que a aceitação desse desejo serve como alicerce para relações mais transparentes para consigo e com pessoas mais próximas (Paiva, 2007; Campos, 2015). Segue exemplo de fala da participante: "Porque as pessoas heteros que a gente convive só dão vontade da gente contar pra todo mundo, porque são muito abertas, trata como se fosse um casal hetero, a coisa mais normal do mundo. [...] Então é como se [a gente] fosse um casal mesmo, entendeu?".

Nesse contexto, nem mesmo a coabitação é suficiente para a afirmação de uma identidade lésbica ou bissexual. Como um mecanismo contraditório, Paiva (2007) afirma que a experiência de coabitação, ao mesmo tempo em que supostamente confere maior visibilidade ao relacionamento, pode também se beneficiar da "ética da reserva", ou seja, 
pode ser um fator que contribui ainda mais para a invisibilização desses relacionamentos, na medida em que o ambiente doméstico se torna uma refúgio às ameaças exteriores.

Duas de nossas entrevistadas optaram por não definir suas identidades sexuais, sendo que os motivos são: uma não se define por "se atrair mais por pessoas, independente se é homem ou mulher" (Luana), e outra porque ainda não "entende" essa questão (Laís). As outras três participantes se definem como lésbicas, embora uma delas afirme que "está" lésbica (Dayane) e as outras (Mickaely e Sibel) não excluem a possibilidade de, futuramente, se relacionarem com homens, ainda que achem isso pouco provável e que não tenham relacionamentos com homens relatados em seus históricos de vida. Importante ressaltar também que nenhuma delas mencionou a palavra "bissexual" no contexto da entrevista.

As afirmações de nossas participantes preconizam o entendimento de que existe uma dificuldade de as mulheres se identificarem como lésbicas por uma série de fatores. As entrevistadas que têm em seus discursos mais referências a padrões heterossexuais de relacionamento (Luana e Laís) são as que não se definem em termos homossexuais; e as que têm mais tentativas de distanciamento da figura da fancha, ${ }^{3}$ figura essa que expressa a radicalização da recusa do outro sexo, o símbolo da "verdadeira homossexual", a mulhermacho (Heilborn, 2004).

Almeida e Heilborn (2008) apontam que não são só os comportamentos sexuais (relacionar-se com outra mulher) que vão ditar o reconhecimento da identidade lésbica, mas que estão presentes significados de múltiplos símbolos (inclusive corporais) na construção dessa identidade. Assim sendo, "o 'não-assumir' pode estar associado simplesmente ao desinteresse por alguns símbolos e comportamentos associados à lesbianidade" (Almeida \& Helborn, 2008, p. 233); e os discursos de nossas entrevistadas revelam uma possível ancoragem dessas mulheres nas crenças do senso comum a respeito da figura da lésbica. Laís, por exemplo, diz que

Ela veste roupa de homem, ela não veste roupa de menina não. Que ela é o homem e eu sou a mulher, entendeu? Aí ela fica de homenzinho e eu fico com medo, porque a gente anda junto e tudo, mas nada de mãozinha dada, essas coisas. A gente anda tipo como

\footnotetext{
${ }^{3}$ Mulher lésbica masculinizada.
} 
fosse amiga. Eu já vi também outras mulheres se beijando na boca. Nossa, as mulher são doida. Porque as pessoas às vezes falam no ponto de ônibus: "nossa, olha lá: mulher com mulher se beijando. Falta de respeito. Não respeita nem a criança no ponto de ônibus". E também das minhas filhas também, porque quando eu fui morar nesse prédio aqui eles sabiam que eu era, né, vamos dizer. Como que eu posso falar que nós duas somos? Como que fala? É gay que fala? Sapatão? Lésbica? Sei lá.

Meireles (2013, p. 222) chama atenção para algo que ela nomeia de "receio da visibilidade", que faz com que muitas vezes as mulheres lésbicas se utilizem de ferramentas no cotidiano de maneira a passarem despercebidas, sendo que

O medo de ser descoberta, a apreensão, a vergonha, a negação da homossexualidade, as máscaras para ocultar a orientação sexual (uso de acessórios femininos, invenção de história de namorado ou noivo), enfim, o estresse cotidiano em razão do medo da "descoberta do segredo" afeta sobremaneira a saúde mental das mulheres lésbicas.

Os recursos utilizados a fim de deixar a preferência sexual passar despercebida geram certo "modo clandestino de sobrevivência" (Meireles, 2013) nessas mulheres, que pode ser entendido como um recurso frente à lesbofobia de demarcar a feminilidade a partir de estereótipos difundidos socialmente, a fim de não levantar suspeita. Luana, por exemplo, revela que sua infância e adolescência foram marcadas por uma insistente tentativa de se feminilizar ao máximo, devido aos enunciados que chegavam até ela a respeito de sua aparente masculinização. Os vestígios desse passado, em que houve uma tentativa de apagamento de si ao tentar transformar-se em outro, por assim dizer, se atualiza no presente em suas estratégias de manutenção do "segredo" sobre sua preferência amorosa, na tentativa de referenciar seu relacionamento a um padrão heterossexual e na insistência em não "limitar" sua identidade sexual.

Essas nossas duas interlocutoras que optaram ou não souberam definir suas identidades sexuais foram as que, durante a entrevista, demonstraram maior desgaste emocional, gerado pela tentativa de ajustamento discursivo ao padrão heterossexual, tendo 
isso, por vezes, refletido em seus relacionamentos. Isso evidencia o possível efeito que o enquadramento identitário pode ter na saúde mental, uma vez que pesquisas apontam que a afirmação do "orgulho" é importante para a ressignificação de elementos dolorosos da história pessoal (Almeida \& Heilborn, 2008).

Entretanto, Aquino (1995) sugere que a autorreferência como "lésbica" é uma prerrogativa de ativistas homossexuais feministas, utilizada sobremaneira como forma de enfatizar o aspecto político da orientação sexual homossexual. Almeida e Heilborn (2008) apontam que essa é primordialmente uma identidade de resistência, constituída em meio a tentativas de novas atribuições de significado a experiências dolorosas do passado. Uma de nossas entrevistadas, por exemplo, conta que percebeu a importância de se assumir lésbica depois de passar por uma situação de preconceito na família.

Dessa forma, as diligências de ocultamento da lesbianidade, o medo de falar sobre si e a negação da própria sexualidade surgem como resultado, entre outros tipos, da "violência simbólica e psicológica a que as mulheres de modo geral estão sujeitas unicamente por serem mulheres, mas ulteriormente agravadas quando outros marcadores sociais incidem sobre seu gênero, como a orientação sexual e raça" (Meireles, 2013, p. 225).

A lesbofobia está incluída no escopo daquilo que é chamado de homofobia. Borrillo (2016, p. 13) define a homofobia como "uma manifestação arbitrária que consiste em designar o outro como contrário, inferior ou anormal" e como a consequência de uma representação social que, "pelo fato de outorgar o monopólio da normalidade à heterossexualidade, fomenta o desdém em relação àquelas e àqueles que se afastam do modelo de referência" (p. 23).

Entretanto, a lesbofobia é entendida como uma forma de homofobia específica destinada às mulheres lésbicas (Borrillo, 2016), constituindo-se com uma especificidade particular, definida pelo duplo desdém direcionado à mulher lésbica pelo fato de ser mulher e homossexual. A mulher lésbica, portanto, acumula discriminações contra seu gênero (misoginia) e contra sua sexualidade (lesbofobia). O autor aponta ainda a caracterização das lésbicas nas relações sociais fundamentadas na opressão de gênero, que acabam sendo invisíveis e silenciosas. Conforme já explanado na introdução deste trabalho, tornar a sexualidade da mulher lésbica invisível está no cerne da violência que as atinge. 
Todas as participantes relatam já terem passado por situações de preconceito, independentemente do modo como essa discriminação ocorreu. Uma de nossas entrevistadas conta, por exemplo, disse que desde pequena foi interpelada com termos pejorativos que se referiam a ela como "machinho", como alguém que "parecia um menino" (Luana). Relata, ainda, que por muitos anos tentou performar uma feminilidade estereotipada, o que culminou, inclusive, na demora e no sofrimento em aceitar o desejo afetivo-sexual por outras mulheres, por medo de confirmar a desconfiança das pessoas de que ela era de fato um "menino".

Eu tinha um jeito mais largado, assim, eu era mais largada sabe, e as pessoas viam isso como jeito de menino. Já aconteceu vários episódios que me chateou muitas vezes. Então, tipo, eu era nova e já ouvi muitas vezes "ai, parece um menininho, parece um machinho", e aí eu já tive muitas vezes de querer me portar muito mais feminina do que eu era... [...] E então, por eu ouvir muito isso [que parecia um menino], eu tinha medo de transparecer isso, entende? Eu queria usar salto, porque toda menina usava salto, não que eu gostasse. [...] [Minhas amigas] se beijavam todas na maior zoeira [...]. E eu sempre evitei. Sempre evitei. Aí um dia eu fui e beijei uma, assim, zoando e tal, mas foi só uma e tal, e mesmo assim eu tinha um pouco de receio. E eu acho que esse receio todo era porque eu gostava, talvez, só que eu não queria que aquilo fosse real, então eu fugia disso.

De um corpo inscrito em uma matriz regulatória espera-se concordância entre sexo/gênero/desejo: ou seja, de um sexo biológico feminino, espera-se o reconhecimento de uma identidade de gênero feminina e um desejo heterossexual; todo e qualquer desvio fora desse padrão é considerado incivilizado e antinatural (Butler, 2016). Nesse sentido, podemos considerar que a parceria homoerótica representa, de alguma forma, uma ruptura em relação às práticas regulatórias que constituem essa coerência. Entretanto, por meio do relato de nossa interlocutora, percebemos que essa ruptura pode ser apenas parcial, havendo tentativas de que ela não afete as demais convenções de feminilidade, "que podem ser reiteradas ou subvertidas a partir das práticas sociais" (Meinerz, 2011, p. 101). Por exemplo: colocar-se como discreta no espaço público reitera as expectativas que recaem sobre o gênero feminino (Bordieu, 2009) e evidencia as performances de feminilidade 
apontadas por Meireles (2013), as quais muitas mulheres lésbicas se sentem obrigadas a representar.

Sabemos que, especialmente para as mulheres, os enunciados da heterossexualidade compulsória chegam de maneira sistemática, pois ensejam a manutenção da hierarquia entre os gêneros. Compelir uma mulher à heterossexualidade é necessário para a sustentação da sua condição reprodutora, passiva, maternal, controlada e submissa. Falquet (2012) defende que as relações sociais entre os gêneros são pautadas não sobre uma premissa de gênero, mas sobre o princípio da heterossexualidade e que a hegemonia masculina se dá sob premissas patriarcais e de imposição da heterossexualidade procriativa para as mulheres e sua consequente interdição à homossexualidade feminina.

De fato, existe a ideia de que a heterossexualidade é um mecanismo natural de atração entre dois sexos. Entretanto, Rich (2010) e Wittig (1970) também renegam a heterossexualidade como uma inclinação natural dos seres humanos e afirmam que esta é imposta às mulheres por meio de mecanismos complexos e violentos, econômicos e ideológicos, simbólicos e políticos (Falquet, 2012). Para Rich (2010), a heterossexualidade se torna uma norma obrigatória com a invisibilização da existência lésbica.

As reverberações dessa norma se atualizam nas falas de nossas participantes, quando, por exemplo, uma delas conta que se sentiu "surpresa" quando percebeu que poderia sentir tesão por uma mulher da mesma forma como sentia por um homem, pois, na sua cabeça, isso não era possível. Se para as mulheres de modo geral é negado o direito à livre experiência sexual, uma vez que não são educadas para o prazer, para as lésbicas isso se apresenta de maneira ainda mais rígida, devido às referências sobre sexo serem sempre alusivas à masculinidade e à genitalização do desejo sexual.

Além de comparecem muitas vezes como violência direta, parte desses discursos também é internalizado pelas mulheres. Todas as participantes fazem afirmações que revelam que a lesbofobia se apresenta para essas mulheres como algo que as limita e as impede de fazer determinadas escolhas. Luana, por exemplo, se priva de "andar de mãos dadas" e afirma que não demonstra qualquer tipo de afeto pela companheira na rua, pois procura "respeitar" as pessoas; Mickaely diz que "você mesmo acaba se punindo", evitando ter determinadas atitudes como maneira de evitar confrontos ou sofrer retaliações; Sibel 
conta que sua reação diante de uma situação de discriminação foi ficar "em choque", "sem reação"; Mickaely também justifica o fato de as pessoas se referirem a elas como amigas devido ao modo como elas se tratam. Estudos apontam que muitas mulheres lésbicas se omitem perante situações de discriminação em função da internalização de valores pelos quais as mulheres geralmente são socializadas, e as mulheres lésbicas em especial (Meireles, 2013).

Esses valores dizem respeito a toda produção daquilo que é chamado de "generificação", ou seja, aquilo que torna um corpo como parte de um gênero masculino ou feminino. No caso das mulheres, esses valores dizem respeito às concepções de feminilidade hegemônicas que associam o "ser mulher" à beleza; magreza; sensualidade; delicadeza; docilidade; obediência; discrição; comedimento; subordinação ao homem; amor romântico; monogamia e à maternidade (Bordini \& Sperb, 2012). Borrillo (2016, p. 101) explica que não é incomum que o ódio da sociedade contra os homossexuais se transforme em ódio de si mesmo, afinal, "em uma sociedade em que os ideais de natureza sexual e afetiva são construídos com base na superioridade psicológica e cultural da heterossexualidade, parece difícil esquivar os conflitos interiores resultantes de uma não adequação a tais valores".

Ocorre, dessa forma, uma interiorização da violência que faz com que boa parte das pessoas homossexuais tente lutar contra seus desejos, sendo os principais agentes que provocam a homofobia interiorizada a intolerância social e os preconceitos individuais (Borrillo, 2016). Percebemos esses elementos muito presentes no discurso das nossas participantes, o que provoca, entre elas, a constituição de estratégias de gestão dessa sexualidade.

Existe uma ideia difundida no imaginário social que faz pensar que é quando o desejo homossexual se mostra "aparente" que ocorre a possibilidade de as pessoas serem vítimas de alguma forma de preconceito, e que, por isso, as mulheres mais masculinizadas tendem a sofrer mais preconceito (Monteiro, Machado \& Nardi, 2011) - pois o senso comum costuma associar a performance de gênero (mais ou menos masculinizada) ao desejo sexual, fazendo com que uma mulher mais "masculina" seja imediatamente vista como "lésbica". 
A homossexualidade é entendida como um "segredo fundante" (Pecheny, 2004), ou seja, não é aparente, a não ser que o sujeito adote trejeitos corporais que revelem tal condição. Dessa forma, as mulheres que não "aparentam" ser lésbicas podem receber o benefício da dúvida; portanto, "não aparentar" está dentro do esboço de estratégias utilizadas por elas no enfrentamento à discriminação, conforme exemplificado anteriormente por Luana (que passou parte da infância e adolescência se forçando a performar feminilidade) e Laís (que diz evitar andar de mãos dadas com a namorada na rua).

Outra entrevistada (Sibel) fala sobre isso quando diz acreditar ser mais fácil para uma mulher se assumir lésbica do que para um homem se assumir gay ("pra mulheres é mais tranquilo, tanto é que raramente você vê homens andando de mãos dadas na rua"), atribuindo isso à

cultura machista. Porque hoje em dia as pessoas associam, hoje em dia não, sempre foi associado às lésbicas a questão pornô, a sexualidade mais aflorada, alguma coisa assim, então as pessoas associam mais assim. Homens não, homens, por conta do machismo, os homens têm medo dos gays atacarem como eles atacam as mulheres.

Um apontamento a ser feito a respeito da afirmação de Sibel de que mulheres têm mais facilidade no coming out tem a ver com a maneira como o relacionamento entre duas mulheres foi/é visto pela nossa sociedade historicamente.

Ellis, em 1897, afirmou que a homossexualidade feminina era mais difícil de ser detectada do que a masculina porque a intimidade entre mulheres é maior que entre homens, o que dificulta a suspeita da existência de uma paixão anormal entre elas. Em contrapartida, Louro (2016) aponta que, entre meninos e homens, a vigilância da manifestação de afetividade é muito mais intensa do que entre meninas e mulheres. Dessa forma, afirmar que não há preconceito, ou que existe menos preconceito, pode significar também não haver reconhecimento da legitimidade dessas relações.

As práticas afetivas entre meninas e mulheres costumam ter, entre nós, um leque de expressões mais amplo do que aquele admitido 
para garotos e homens. A intimidade cultivada nas relações de amizade entre mulheres e a expressão da afetividade por proximidade e toques físicos são capazes de borrar possíveis divisórias entre relações de amizade e relações amorosas e sexuais. Daí que a homossexualidade feminina pode se constituir de forma mais invisível. Abraços, beijos, mãos dadas, a atitude de "abrir o coração" para a amiga/parceira são práticas comuns do gênero feminino em nossa cultura. (Louro, 2016, p. 91).

De acordo com o que pudemos observar, existem algumas formas de gestão dessa sexualidade, sendo que essas maneiras são fluidas e impessoais; nossas entrevistadas parecem passear por esses limites e adotam uma ou outra postura, dependendo do que a situação exige. Dessa forma, temos discursos que ora lançam mão da invisibilidade, chegando a impor esse silenciamento à parceira, ora exigem um lugar de reconhecimento; discursos que ora justificam preconceitos, ora os condenam veemente; formas de subjetivação que escolhem a dedo a quem pode revelar o "segredo" e a quem não pode.

O "segredo" do relacionamento homoerótico funda as formas pelas quais as mulheres lésbicas vão se relacionar com os outros e com os espaços (Pecheny, 2004). O ambiente de trabalho, quando se articula entre a revelação ou não da homossexualidade, sugere medos e receios nos relatos das entrevistadas: seja a exigência do silenciamento da parceira; seja a omissão em uma entrevista de emprego; seja a escolha de não mais trabalhar: tudo isso sugere formas de enfrentamento aos efeitos da lesbofobia e sugere que essas maneiras são múltiplas, diversas e até mesmo contraditórias.

Entretanto, esse esforço de controle das situações de vida, a divisão de amigos/as entre aqueles/as que podem saber e aqueles/as que não, as invenções de estratégias para evitar o assunto, as respostas evasivas, os segredos que têm que manter uma coerência no tempo demandam uma energia psíquica intensa. (Monteiro et al., 2011, p. 130).

Todas as participantes passam por situações em que seus relacionamentos parecem não ter legitimidade como um relacionamento amoroso. Esse enunciado aparece de variadas formas em seus relatos: o casal é visto como "amigas"; como "a menina que mora junto"; 
como "irmãs". O status de amizade também parece ser utilizado pelas participantes, muitas vezes, como estratégia no enfrentamento à lesbofobia, como maneira de passar despercebida. Heilborn (2004) aponta que o status de "amiga" é uma denominação ambígua, uma vez que, se por um lado reconhece a condição de parceira, por outro desqualifica essa relação. Podemos observar essas nuances no discurso de Mickaely:

Ah, as pessoas sempre tratam a gente como uma relação de amizade. Porque a gente é muito amigas, a gente tem uma relação de amizade muito grande. É o que eu falei, perto de todo mundo a gente não fica tão assim, não que a gente não demonstre, a gente demonstra, se abraça e tudo o mais. Mas todo mundo que chega pergunta se a gente é irmã. Ou amiga ou irmã. Às vezes, dependendo de quem for, se for uma pessoa de idade, eu falei é, é minha amiga, nem vou perder tempo discutindo, explicando nada. Mas a maioria das pessoas perguntam se nós somos irmãs. Eu ainda falei: "mas poxa, não tem nada a ver fisicamente". Ela é mais morena, eu sou mais branca, ela tem um narigão, eu tenho o nariz mais "batatudinho". Eu tenho o cabelo liso, ela tem o cabelo cacheado. Só se for porque a gente é gorda, porque de igual não temos mais nada [risos].

O discurso também pode ser permeado por nuances que evidenciam possíveis marcas de uma lesbofobia internalizada e de uma maneira de pensar o mundo constituída por meio de noções estáticas sobre sexo e gênero, utilizando-se de afirmações como "por ser duas mulheres, já não é o tradicional"; "tinha medo de transparecer isso [que gostava de mulheres]"; "assim como um homem e uma mulher"; "como se fosse mesmo namorada"; "como se fosse duas pessoas que namoram"; "como se fosse um casal hetero"; "evito pra respeitar as pessoas que não concordam"; "[uma mulher] entende a fragilidade [da mulher]".

Luana, por exemplo, justifica o fato de não se assumir devido à existência de uma sociedade que seria indubitavelmente homofóbica, cuja existência é o motivo pelo qual ela "se priva de muita coisa"; ao mesmo tempo, afirma que não se importa com o que a sociedade pensa e se preocupa apenas com uma possível rejeição familiar; em contrapartida, demonstra surpresa quando as colegas de trabalho da companheira a acolhem e não acredita que sua família a rejeitaria quando soubesse. Tais discursos evidenciam um forte conflito pessoal, que ora é marcado por discursos de "evolução", segundo ela - por exemplo, 
quando diz que não se considera hetero ou lésbica, pois já se "desligou disso" -, ora é marcado por intenso sofrimento e medo por alguma discriminação que tenha sofrido ou possa vir a sofrer.

Luana afirma que ela e a companheira convivem mais com pessoas heterossexuais do que com pessoas homossexuais, e que essas pessoas são muito abertas e as tratam "como se fosse um casal hetero". Em estudo realizado por Cerqueira-Santos, Santos, Salles, Longo \& Teodoro (2007) realizado com 200 estudantes de uma universidade, foi constatado que heterossexuais que interagem com indivíduos LGBTIs têm mais propensão a desenvolver atitudes positivas com as minorias sexuais. Perucchi (2001), ao analisar a importância do gueto para a construção de subjetividades, afirma que, se por um lado, o "gueto gay" reflete a lógica excludente da sociedade de manter esses sujeitos à margem, por outro ele é fundamental para a percepção de que se está "entre iguais" e para a sensação de "proteção". Dessa forma, a dificuldade de nossa participante em "assumir" o seu relacionamento aponta a dificuldade que os casais homossexuais têm muitas vezes de se reconhecer como casal, uma vez que, sem o reconhecimento social, a dimensão externa necessária à constituição da identidade social do casal ficaria prejudicada (Heilborn, 2004).

\section{Considerações finais}

Percebemos que a violência do tipo simbólica provoca o apagamento social, político, moral, psicológico e afetivo da existência do amor entre mulheres. À invisibilidade da existência desse modo de constituir-se no mundo soma-se a dificuldade que a sociedade tem de compreender o que são e como se relacionam duas mulheres juntas. É possível perceber que nas mídias, nas artes, na política e nas ciências como um todo existem muitas limitações acerca do entendimento sobre esses relacionamentos e dos anseios e necessidades dessas mulheres. A intervenção psicológica no plano individual não pode, nunca, estar desatrelada da intervenção no campo social, político e ideológico, uma vez que o preconceito é um vetor que atinge diretamente a produção de subjetividade dos sujeitos, pois interfere no modo como estes constituem suas identidades e percebem a si mesmos. 
É importante que, por meio também da produção científica, se criem novos territórios, tanto sociais quanto subjetivos, para representar e mostrar que outro modo de existência é possível e que, se são necessárias estratégias de gestão da sexualidade que visem "escondê-la", elas são indispensáveis somente porque ainda existe o imperativo LGBTfóbico, e ainda é necessário travar uma batalha contra todo um sistema que oprime corpos e subjetividades.

Conhecendo mais a fundo as experiências amorosas de nossas participantes, podemos perceber as particularidades vivenciadas por elas e também o que as aproximam. Conhecemos histórias de vida diversas, mulheres que se assumiram ainda adolescentes, outras que se assumiram depois de anos de casamentos com homens; mulheres que performam feminilidade, outras não; mulheres que veem seus relacionamentos como principal elemento de suas vidas, outras não; mulheres mães, já outras que não querem ser; mulheres estudantes, donas de casa, trabalhadoras, com níveis de escolaridade diversos; mulheres que sofrem com a dificuldade de aceitar o desejo que sentem, e que sentem medo de expressá-lo nessa sociedade que as colocam na marginalidade, mas que, em meio a tantas dores, se firmam em parcerias de afeto sólidas e seguras com outras mulheres.

Para pesquisas futuras, sugere-se aprofundar nos efeitos das violências sofridas por essas mulheres, bem como utilizar marcadores de classe e raça como método de análise, uma vez que se sabe que essas interseções são direcionadoras e interferem diretamente na existência dos sujeitos. Além disso, sugere-se também aprofundar em aspectos mais específicos da dinâmica conjugal, como o compartilhamento de tarefas domésticas e a existência (ou não) de violência conjugal.

\section{Referências}

Almeida, G., \& Heilborn, M. L. (2008). Não somos mulheres gays: identidade lésbica na visão de ativistas brasileiras. Revista Gênero, 9(1), Niterói, Rio de Janeiro.

Andrade, C. C., \& Holanda, A. F. (2010). Apontamentos sobre pesquisa qualitativa e pesquisa empírico-fenomenológica. Estudos de Psicologia, 27(2), 259-268.

Aquino, L. O. R. (1995). Discurso lésbico e construções de gênero. Horizontes Antropológicos, Porto Alegre, 1(1), 79-94. 
Bordini, G. S., \& Sperb, T. M. (2012). Concepções de gênero nas narrativas de adolescentes. Psicologia: reflexão e crítica, Porto Alegre, 25(4),738-746.

Borrillo, D. (2016). Homofobia: história e crítica de um preconceito. Barcelona: Bellaterra. Bourdieu, P. (2009). A dominação masculina. Rio de Janeiro, Rio de Janeiro: Bertrand Brasil. Butler, J. (2016). Corpos que pesam: sobre os limites discursivos do "sexo". In G. L. Louro (Org.). O Corpo Educado: pedagogias da sexualidade. Belo Horizonte: Autêntica Editora.

Campos, L. S. (2015). O bem-estar de homossexuais: associações com o apoio social familiar, resiliência, valores e religiosidade. Dissertação de mestrado, Programa de Pós-Graduação em Psicologia, Universidade Federal do Espírito Santo, Vitória, Espírito Santo.

Cerqueira-Santos, E., Santos, W. F., Salles, L. A., Longo, J. L., \& Teodoro, M. (2007). Contato interpessoal e crenças sobre homossexualidade: desenvolvimento de uma escala. Interação em Psicologia, 11 (2).

Coutinho, S. M. S. (2008). A dona de tudo: o que é ser mulher, mãe e esposa de acordo com as representações sociais de mulheres de duas gerações. Tese de doutorado, Programa de Pós-Graduação em Psicologia, Universidade Federal do Espírito Santo. Vitória, Espírito Santo.

Decastro, T. G., \& Gomes, W. B. (2011). Aplicações do método fenomenológico à pesquisa em Psicologia: tradições e tendências. Estudos de Psicologia, 28(2), 153-161.

Defendi, E. L. (2010). Homoconjugalidade masculina, revelação e redes sociais: um estudo de caso. Dissertação de mestrado, Programa de Pós-Graduação em Psicologia Clínica, Pontifícia Universidade Católica de São Paulo, São Paulo, São Paulo.

Falquet, J. (2012). Romper o tabu da heterossexualidade: contribuições da lesbianidade como movimento social e teoria política. Cadernos de Crítica Feminista, Recife, VI(5), 8-31.

Féres-Carneiro, T. (1999). Conjugalidade: um estudo sobre as diferentes dimensões da relação amorosa heterossexual e homossexual. In T. Féres-Carneiro (Org.). Casal e família: entre a tradição e a transformação (p. 96-117). Rio de Janeiro, Rio de Janeiro: NAU Editora.

Féres-Carneiro, T. (2001). Casamento contemporâneo: construção da identidade conjugal. In T. Féres-Carneiro (Org.). Casamento e família: do social à clínica (pp. 67-80). Rio de Janeiro: NAU Editora.

Féres-Carneiro, T., \& Diniz Neto, O. (2010). Construção e dissolução da conjugalidade: padrões relacionais. Paidéia, 20(46), 269-278.

Heilborn, M. L. (2004). Dois é par: gênero e identidade sexual em contexto igualitário. Rio de Janeiro, Rio de Janeiro: Editora Garamond.

Louro, G. L. (2016). O corpo educado: pedagogias da sexualidade. Belo Horizonte: Autêntica Editora.

Luz, R. R. (2015). Conjugalidades possíveis: um estudo sobre relacionamentos homossexuais. Rio de Janeiro, Rio de Janeiro: Editora Multifoco.

Meinerz, N. E. (2011). Entre mulheres: etnografia sobre relações homoeróticas femininas em segmentos médios urbanos na cidade de Porto Alegre. Rio de Janeiro: EdUERJ. 
Meireles, A. C. (2013). Docentes sexuadas: mulheres lésbicas e prática escolar. In H. Pinel \& Filho, C. M. (Orgs.). Diversidade sexual: silêncio, diálogo e currículo (pp. 221-238). São Carlos: Pedro e João Editores.

Miskolci, R. (2007). Pânicos morais e controle social. Cadernos Pagu, 28, 101-128.

Monteiro, L. F., Machado, P. S., \& Nardi, H. C. (2011). Do armário à armadura: estratégias de mulheres no enfrentamento da homofobia e do heterossexismo. Revista Polis $e$ Psique, 1(3), 112.

Moreno, M. (1999). Como se ensina a ser menina: o sexismo na escola. São Paulo: Editora da Unicamp.

Muniz, J. O. (1992). Mulher com mulher dá jacaré: uma abordagem antropológica da homossexualidade feminina. Dissertação de mestrado em Antropologia Social, PPGAS-MN-UFRJ, Rio de Janeiro.

Nascimento, G. C. M., Scorsolini-Comin, F., Fontaine, A. M. G. V., \& Santos, M. A. D. (2015). Relacionamentos amorosos e homossexualidade: revisão integrativa da literatura. Temas em Psicologia, 23(3), 547-563.

Paiva, A. C. S. (2007). Reserva e invisibilidade: a construção da homoconjugalidade numa perspectiva micropolítica. In M. Grossi, A. P. Uziel \& L. Mello (Orgs.). Conjugalidades, parentalidades e identidades lésbicas, gays e travestis (pp. 23-46). Rio de Janeiro: Garamond Universitária.

Pecheny, M. (2004). Identidades indiscretas. In L. F. Rios et al. Homossexualidade: produção cultural, cidadania e saúde (pp. 16-33). Rio de Janeiro, ABIA.

Perucchi, J. (2001). Eu, tu, elas: investigando os sentidos que mulheres lésbicas atribuem às relações sociais que estabelecem em um gueto GLS de Florianópolis. Dissertação de mestrado, Programa de Pós-Graduação em Psicologia, Universidade Federal de Santa Catarina, Florianópolis, Santa Catarina.

Rich, A. (2010). Heterossexualidade compulsória e existência lésbica. Bagoas-Estudos gays: gêneros e sexualidades, 4(5), 17-44. Recuperado de https://periodicos.ufrn.br/bagoas/article/view/2309.

Rodrigues, V., \& Boeckel, M. (2016). Conjugalidade e homossexualidade: uma revisão sistemática de literatura. Nova Perspectiva Sistêmica, 25(55), 96-109.

Souza, E. (2012). Interseções entre homossexualidade, família e violência: relações entre lésbicas na região de Campinas (SP). Sociedade e Cultura, 15(2), 297-308.

Toledo, L. G., \& Filho, F. S. T. (2010). Lesbianidades e as referências legitimadoras da sexualidade. Estudos e Pesquisas em Psicologia, 10(10). Recuperado de http://www.revispsi.uerj.br.

Trindade, Z. A., Menandro, M. C. S., \& Gianórdoli-Nascimento, I. F. (2007). Organização e interpretação de entrevistas: uma proposta de procedimento a partir da perspectiva fenomenológica. In M. M. P. Rodrigues \& P. R. M. Menandro. Lógicas Metodológicas: trajetos de pesquisa em psicologia (pp. 71-92). Vitória, Espírito Santo: GM Editora.

Vainfas, R. (1997). Homoerotismo feminino e o Santo Ofício. In M. D. Priore. História das mulheres no Brasil (pp. 115-140). São Paulo: Contexto.

Wittig, M. (1970). Ninguém nasce mulher. Mulheres Rebeldes. Recuperado de http://mulheresrebeldes.blogspot.com/2009/04/ninguem-nasce-mulher.html. 
Recebido em: 10/9/2018 Aprovado em: 30/6/2019 